\title{
NANOSCIENCE AND NANOTECHNOLOGY IN ENGINEERING
}


This page intentionally left blank 


\title{
NANOSCIENCE AND NANOTECHNOLOGY IN ENGINEERING
}

\author{
Vijay K Varadan \\ University of Arkansas, USA
}

\section{A Sivathanu Pillai Debashish Mukherji Mayank Dwivedi}

Defense Research and Development Organization, India

Linfeng Chen

University of Arkansas, USA 
Published by

World Scientific Publishing Co. Pte. Ltd.

5 Toh Tuck Link, Singapore 596224

USA office: 27 Warren Street, Suite 401-402, Hackensack, NJ 07601

UK office: 57 Shelton Street, Covent Garden, London WC2H 9HE

\section{British Library Cataloguing-in-Publication Data}

A catalogue record for this book is available from the British Library.

\section{NANOSCIENCE AND NANOTECHNOLOGY IN ENGINEERING}

Copyright (C) 2010 by World Scientific Publishing Co. Pte. Ltd.

All rights reserved. This book, or parts thereof, may not be reproduced in any form or by any means, electronic or mechanical, including photocopying, recording or any information storage and retrieval system now known or to be invented, without written permission from the Publisher.

For photocopying of material in this volume, please pay a copying fee through the Copyright Clearance Center, Inc., 222 Rosewood Drive, Danvers, MA 01923, USA. In this case permission to photocopy is not required from the publisher.

ISBN-13 978-981-4277-92-1

ISBN-10 981-4277-92-4

Printed in Singapore. 


\section{Preface}

Nanoscience and nanotechnology involve studying and working with materials at the nanometer scale, and stretch across the whole spectrum of science and technology. Generally speaking, nanoscience concentrates on the fundamental relationships between the physical properties of materials and their nanoscale dimensions, and the underlying sciences for nanoscale synthesis, assembly and characterization. Nanotechnology mainly deals with the design, fabrication and application of nanomaterials. The research and development in nanoscience and nanotechnology require the collaborations between researchers from different disciplines, such as physics, chemistry, materials science, electrical engineering, mechanical engineering and biomedical engineering. The ultimate goal of nanoscience and nanotechnology is to develop materials, devices and systems that outperform the ones developed based on the conventional sciences and technologies, and to create completely novel functionalities.

The advances in nanoscience and nanotechnology exhibit great varieties, and the nanoscience and nanotechnology in engineering is one of the most active and the most important areas in the field of nanoscience and nanotechnology. It directly relates the research activities in nanoscience and nanotechnology to industries and daily life, and numerous nanomaterials, nanodevices and nanosystems for various engineering purposes have been developed and applied for human betterment. Many universities are developing and delivering courses on this area, and we therefore realize the urgent need for an appropriate textbook.

This is the first book that systematically discusses the engineering aspects of nanoscience and nanotechnology from the fundamental level, and includes the breakthrough milestones and the latest developments in this area. It is specially tailored to be a textbook for undergraduates, graduates and those seeking short-term professional trainings. It may also 
serves as a reference desk resource for both academic and industrial researchers interested in this area.

This book consists of eight chapters. Each chapter provides an overview of a specific topic with examples chosen primarily for their educational purposes, and it is organized in a way that fits readers from different science and engineering disciplines. Students are encouraged to expand on the topics discussed in this book by reading the references provided at the end of each chapter.

The first chapter provides the fundamental knowledge of nanoscience and nanotechnology. It starts with introducing the origins of nanoscience and nanotechnology, followed by discussing the general schemes and classification of nanotechnology. The challenges in nanoscience and nanotechnology are analyzed subsequently. Chapter 2 discusses the physical and biological aspects of nanoscience and nanotechnology. After introducing the basics of quantum physics and the fundamentals of nanophysics, the crystal structures and physical properties of materials are discussed, followed by the physical aspects of nanochemistry. After that, the biological aspects of nanoscience and nanotechnology are discussed.

Chapter 3 outlines the technologies for nanoscale fabrication and characterization. These techniques provide the experimental bases for nanoscience and nanotechnology in engineering. This chapter starts with the approaches for nanoscale fabrications, including bottom-up approach and top-down approach. The techniques for characterizing the unique properties of nanomaterials are discussed subsequently, including atomic structure, chemical composition, size, shape and surface area, and the properties of nanoparticles in biological systems.

Based on the fundamental concepts, theoretical backgrounds and experimental techniques discussed in the first three chapters, the following five chapters discuss five important topics on nanoscience and nanotechnology in engineering, including carbon nanomaterials, nanostructured materials, polymer nanotechnology, nanocomposites and organic electronics.

Among different kinds of nanomaterials, carbon nanomaterials are the most popular. Chapter 4 presents a systematic discussion on various types of carbon nanomaterials, including fullerenes, carbon nanotubes 
and carbon nanofoams. For each type of carbon nanostructures, their synthesizing methods, specific properties and typical applications are discussed.

The properties of nanomaterials are strongly dependent on their structures at the nanometer scale. Chapter 5 deals with the synthesis, properties and applications of typical nanostructured materials, including nanopowders, nanoporous materials, nanodusts, nanowires and nanotubes. Special attention is paid on three-dimensional zinc oxide nanostructures.

Chapter 6 concentrates on a special kind of soft nanotechnology, polymer nanotechnology. After introducing electroactive polymers, the fabrication of polymer nanowires, polymer nanotubes, and threedimensional polymer nanostructures are discussed.

Due to their unprecedented combinations of properties, nanocomposites are widely used for engineering applications. Various types of nanocomposites are discussed in Chapter 7, mainly including ceramic matrix nanocomposites, metal matrix nanocomposites, magnetic nanocomposites, polymeric nanocomposites, and nano-bio-composites. At the end of this chapter, a brief discussion is made on smart and intelligent nanocomposites, which are regarded as the future of materials science and technology.

The use of individual molecules, such as carbon nanotubes or other organic compounds, as electronic components offers promising alternatives to current microelectronic devices. Chapter 8 deals with nanoscale electronics with a focus on organic electronics. After discussing the fabrication and properties of pentacene thin films, typical organic sensors and their applications are discussed, with emphasis laid on strain sensors and ion-sensitive field effect transistors.

In preparing this book, it is always kept in our mind to relate the speculative concepts in nanoscience and nanotechnology to practical research and development activities. This book contains our many years of experiences and achievements in this area, and a lot of technical details are released for the first time.

Some of the materials for this book are taken from many lectures and courses we presented around the world. The valuable comments from the participants of these lectures and courses greatly enriched the contents of 
this book. Meanwhile, we would like to indicate that this book is a compilation of the work carried out by many researchers, and we greatly appreciate their valuable contributions in this area. We are also very grateful to the publisher and the staff for their constant encouragement, guidance and support during this project.

There are many people to whom we owe our gratitude for helping us in this process. However, space dictates that only a few of them can receive formal acknowledgements. Our foremost appreciation goes to the research professors and staff of the High Density Electronics Center, University of Arkansas, Fayetteville, in particular, Dr. T. Ji, Dr. H. Yoon and Dr. J. Xie.

In addition, we wish to thank K. Hariharan for helping us in collating the contents of the book and for his constructive suggestions, and Naveen Kalania for his commendable efforts in the design of many diagrams. We would also like to thank the BrahMos Knowledge Centre for providing many inputs for this book.

V. K. Varadan

S. Pillai

D. Mukherji

M. Dwivedi

L. F. Chen 


\section{About the Authors}

Dr. Vijay K. Varadan is currently the Twenty-First Century Endowed Chair in Nano- and Bio-Technology and Medicine, and Distinguished Professor of Electrical Engineering and Distinguished Professor of Biomedical Engineering (College of Engineering) and Neurosurgery (College of Medicine) at University of Arkansas. He is also a Professor of Neurosurgery at the Pennsylvania State University College of Medicine. He joined the University of Arkansas in January 2005 after serving on the faculty of Cornell University, Ohio State University and Pennsylvania State University for the past 32 years. He is also the Director of the Center of Excellence for Nano-, Micro-, and NeuroElectronics, Sensors and Systems and the Director of the High Density Electronics Center. He has concentrated on the design and development of various electronic, acoustic and structural composites, smart materials, structures, and devices including sensors, transducers, Microelectromechanical Systems (MEMS), synthesis and large scale fabrication of carbon nanotubes, NanoElectroMechanical Systems (NEMS), microwave, acoustic and ultrasonic wave absorbers and filters. He has developed neurostimulator, wireless microsensors and systems for sensing and control of Parkinson's disease, epilepsy, glucose in the blood and Alzheimer's disease. He is also developing both silicon and organic based wireless sensor systems with RFID for human gait analysis and sleep disorders and various neurological disorders. He is a founder and the Editor-in-Chief of the Journal of Smart Materials and Structures. $\mathrm{He}$ is the Editor-in-Chief of the Journal of Nanomedical Science in Engineering and Medicine. He is an Associate Editor of the Journal of Microlithography, Microfabrication and Microsystem. He serves on the editorial board of International Journal of Computational Methods. He has published more than 500 journal papers and 14 books. He has 13 patents pertinent to conducting polymers, smart structures, smart antennas, phase shifters, carbon nanotubes and implantable device for Parkinson's patients, MEMS accelerometers and gyroscopes. He is a 
fellow of SPIE, ASME, Institute of Physics, Acoustical Society of America. He has many visiting professorship appointments in leading schools overseas.

Dr. Apathukatha Sivathanu Pillai is presently Distinguished Scientist and Chief Controller, Research and Development, DRDO and CEO and MD, BrahMos Aerospace. Electrical Engineer by profession, Dr. Pillai had an opportunity of working with three great aerospace visionaries of India, Dr. Vikram Sarabhai - Architect of India's Space Programme, Prof. Satish Dhawan - Institution Builder and Dr. APJ Abdul Kalam, Missile Man of India, in Space and Defence Technologies. In the Integrated Guided Missile Development Programme (IGMDP) at DRDO, Dr. Pillai was Programme Director and contributed for realizing critical technologies for guided missile systems, through networking of academic institutions, $\mathrm{R} \& \mathrm{D}$ laboratories and industries, leading to successful results and building indigenous capability in many vital systems. His technology leadership capabilities gave him a unique position of CEO and MD of India-Russia Joint Venture BrahMos Aerospace with responsibilities from design, development, production to market the most advanced supersonic cruise missile BRAHMOS, which has been successfully inducted by the Indian Army and Indian Navy. Dr. Pillai is instrumental in progressing nanotechnology research in many academic institutions through nanotechnology courses, evolving syllabus, projects and establishment of centers. His efforts led to the initiation of design and development of many nanotechnology devices. He also contributed in the development of many societal healthcare products as spin-off from the defense technology. He is Honorary Professor of number of institutions and Fellow and Member of many Professional Societies including IEEE, Indian National Academy of Engineering, Instrument Society of India, Astronautical Society of India. Dr. Pillai was awarded with many honorary degrees from Indian and foreign Universities. Dr. Pillai has published many papers in the international and national journals and has three books to his credit. Among the many awards, he is recipient of the Padmashri awarded by the Government of India in recognition of his distinguished contribution in the field of Science and Engineering. 
Dr. Debashish Mukherji received his Master of Science in Physics in 1986 and Ph.D degree in Physics - Laser Technology (Fabrication of $\mathrm{CO}_{2}$ Laser and Appl. to Materials Processing) from Bhopal University, Bhopal, India in 1989. Dr. Mukherji worked for DRDO from 1991 to 2008 as Senior Scientist and contributed in the full system development, which included sub-system level technologies involving Aeronautics, Mechanical and Chemical Engineering, Laser and Optics and Diagnostics and Instrumentation. He has published 14 papers in national and international journals and reports. He is a member of Indian Laser Association, ILA and many awards to his credit.

Mayank Dwivedi is a Post Graduate in Polymer Science and Engineering and is currently working as a Senior Scientist in Defence Research and Development Organisation, Ministry of Defence, India. $\mathrm{He}$ is currently pursuing his Ph.D from Indian Institute of Technology, New Delhi, India in the area of Polymer Science and Composites.

Dr. Linfeng Chen received his B. Sc. degree in modern applied physics (major) and his B. Eng. degree in machine design and manufacture (minor) from the Tsinghua University, Beijing, China, in 1991, and he received his Ph.D degree in physics from the National University of Singapore in 2001. From 1991 to 1994, he was an Assistant Lecturer in the Department of Modern Applied Physics, Tsinghua University. From 1994 to 1997, he was a Research Scholar with the Department of Physics, National University of Singapore. In 1997, he joined the Singapore DSO National Laboratories, as a project engineer, and two years later, he became a Member of Technical Staff. From 2001 to 2005, he was a research scientist at the Temasek Laboratories, National University of Singapore. From 2005 to 2009, he was a senior research associate at the High Density Electronics Center, University of Arkansas, Fayetteville. Since November 2009, Dr. Chen has been a research assistant professor at the Arkansas Institute of Nanoscale Materials Science and Engineering, University of Arkansas, Fayetteville. He is senior member of IEEE. His research interests mainly include microwave electronics, electromagnetic functional materials, nanomaterials and nanomedicine. 
This page intentionally left blank 


\section{Contents}

Preface $\quad$ v

About the Authors $\quad$ ix

1. Introduction $\quad \mathbf{1}$

1.1 What is nanoscience and nanotechnology?................ 2

1.1.1 Natural and artificial nanoparticles ................. 3

1.1.2 Nanotechnology in ancient time ................... 5

1.1.3 Feynman, Drexler and Taniguchi .................. 7

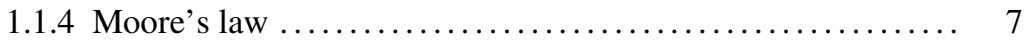

1.2 Effects of making into small $\ldots \ldots \ldots \ldots \ldots \ldots \ldots \ldots \ldots \ldots \ldots$

1.2.1 Size dependence of materials properties.............. 10

1.2.2 Special properties of nanomaterials ................. 11

1.2.2.1 Structural properties $\ldots \ldots \ldots \ldots \ldots \ldots \ldots \ldots \ldots \ldots \ldots, 11$

1.2.2.2 Thermal properties $\ldots \ldots \ldots \ldots \ldots \ldots \ldots \ldots \ldots \ldots \ldots 11$

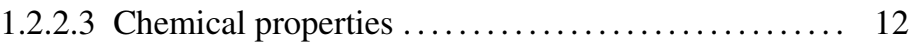

1.2.2.4 Mechanical properties .................. 12

1.2.2.5 Magnetic properties ................... 13

1.2.2.6 Optical properties $\ldots \ldots \ldots \ldots \ldots \ldots \ldots \ldots \ldots \ldots \ldots$

1.2.2.7 Electronic properties $\ldots \ldots \ldots \ldots \ldots \ldots \ldots \ldots \ldots \ldots \ldots$

1.2.2.8 Biological properties ................. 15

1.3 General themes and classification of nanotechnology........... 15

1.3.1 General themes of nanotechnology ................ 15

1.3.1.1 Characterization tools $\ldots \ldots \ldots \ldots \ldots \ldots \ldots \ldots \ldots \ldots 16$

1.3.1.2 Nanoscale science .................... 16

1.3.1.3 Molecular level computation................ 16

1.3.1.4 Fabrication and processing technology ......... 16

1.3.2 Classification of nanotechnology ................. 17

1.4 Challenges in nanoscience and nanotechnology .............. 17

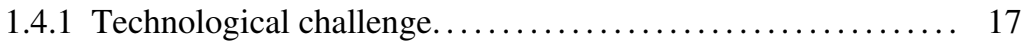

1.4.2 Societal and ethical challenge $\ldots \ldots \ldots \ldots \ldots \ldots \ldots \ldots \ldots \ldots$

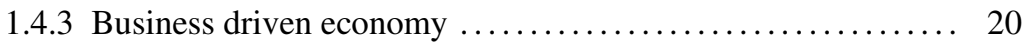

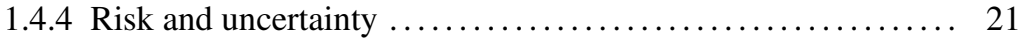

1.4.5 Security and military implications ................ 22

1.4.6 Emerging concern from nanoparticles $\ldots \ldots \ldots \ldots \ldots \ldots \ldots 22$ 
2. Physical and Biological Aspects of Nanoscience and Nanotechnology 27

2.1 Basics of quantum physics............................. 27

2.2 Fundamentals of nanophysics.......................... 28

2.2.1 Electron levels for atoms and solids .................. 29

2.2.1.1 Atoms................................ 29

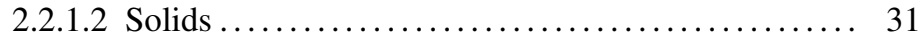

2.2.2 Electron levels for nanostructures $\ldots \ldots \ldots \ldots \ldots \ldots \ldots \ldots, 33$

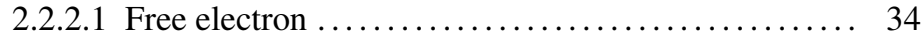

2.2.2.2 Electron in a finite potential well .............. 34

2.2.2.3 Electron in an infinite potential well ............ 35

2.2.2.4 Schrödinger equations ....................... 35

2.2.3 Density of states and confinement .................. 37

2.2.3.1 Zero-dimensional solid ..................... 38

2.2.3.2 One-dimensional quantum wire.............. 38

2.2.3.3 Two-dimensional thin film ................... 39

2.2.3.4 Particle in a three-dimensional box ............. 40

2.3 Crystal structures and physical properties ................... 40

2.3.1 Cubic crystal lattice structures...................... 42

2.3.2 Symmetry in crystals ........................... 43

2.3.3 Bravais lattices and point/space groups ............... 45

2.3 .4 Quasicrystals.................................. 45

2.3.5 Liquid crystals ............................... 45

2.4 Physical aspects of nanochemistry ...................... 47

2.4.1 Nomenclature and periodic table of elements ............ 47

2.4.2 Surface energy of nanostructured materials .............. 48

2.5 Bionanoscience and bionanotechnology .................... 51

2.5 .1 Basic concepts ................................ 51

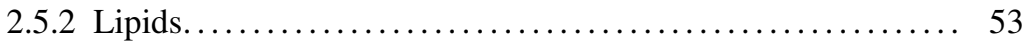

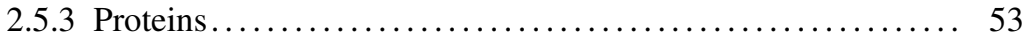

2.5.4 Biomimetic polypeptides......................... 55

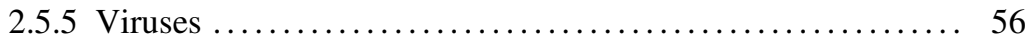

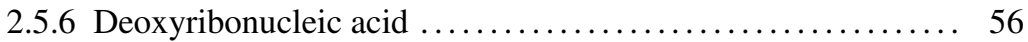

2.5.6.1 Structures of DNA ........................ 57

2.5.6.2 Nanoparticles and DNA .................... 59

2.5.6.3 DNA electronics .......................... 60

2.5.6.4 DNA computing.......................... 60

2.5.7 Biological neuronal networks $\ldots \ldots \ldots \ldots \ldots \ldots \ldots \ldots \ldots . \ldots 6$

2.5.8 Artificial neuronal networks $\ldots \ldots \ldots \ldots \ldots \ldots \ldots \ldots \ldots \ldots . \ldots 3$

2.5.8.1 Neural networks and conventional computers ...... 63

2.5.8.2 Biological neuronal cells on silicon.............. 65

2.5.9 Molecular biomimetics........................... 65 
3. Nanoscale Fabrication and Characterization $\quad \mathbf{7 1}$

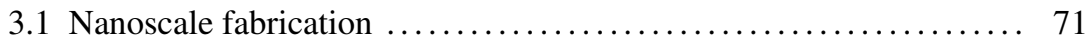

3.1.1 Bottom-up approach ........................... 72

3.1.1.1 Chemical synthesis ...................... 72

3.1 .1 .2 Self-assembly $\ldots \ldots \ldots \ldots \ldots \ldots \ldots \ldots \ldots \ldots \ldots, 73$

3.1.1.3 Positional assembly ...................... 74

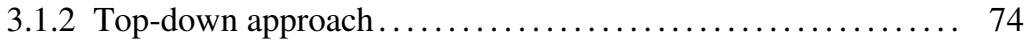

3.1.2.1 Photolithography ........................ 75

3.1.2.2 Electron beam lithography.................. 76

3.1.2.3 Focused ion beam lithography ............... 78

3.1.2.4 Dip-pen nanolithography $\ldots \ldots \ldots \ldots \ldots \ldots \ldots \ldots$

3.1.2.5 Extreme ultraviolet lithography ............... 81

3.1.2.6 Nanoimprint lithography $\ldots \ldots \ldots \ldots \ldots \ldots \ldots \ldots . \quad 82$

3.1.2.7 Contact lithography $\ldots \ldots \ldots \ldots \ldots \ldots \ldots \ldots \ldots \ldots \ldots$

3.1.2.8 X-ray lithography $\ldots \ldots \ldots \ldots \ldots \ldots \ldots \ldots \ldots \ldots$

3.1.2.9 Lift-off lithography....................... 87

3.1.2.10 Soft lithography ........................... 88

3.2 Characterization of nanomaterials....................... 89

3.2.1 Atomic structure and chemical composition ............. 90

3.2.1.1 Vibrational spectroscopies................... 90

3.2.1.2 Nuclear magnetic resonance .................. 91

3.2.1.3 X-ray and UV spectroscopies ................. 91

3.2.1.4 X-ray and neutron diffraction................. 93

3.2.2 Size, shape and surface area ..................... 94

3.2.2.1 Electron microscopy....................... 94

3.2.2.2 BET and pycnometry $\ldots \ldots \ldots \ldots \ldots \ldots \ldots \ldots \ldots$

3.2.2.3 Epiphaniometer ......................... 97

3.2.2.4 Zeta potential analyzer ................... 97

3.2.2.5 Laser granulometry....................... 98

3.2.2.6 Elliptically polarized light scattering ........... 98

3.2.2.7 Gas adsorption ............................ 99

3.2.2.8 Positron annihilation ....................... 100

3.2.2.9 Mercury porosimetry ..................... 101

3.2.3 Nanoparticles in biological systems ................. 101

$\begin{array}{ll}\text { 4. Carbon Nanomaterials } & 107\end{array}$

4.1 Carbon allotropes ....................................... 107

4.2 Fullerenes ........................................... 109

4.2.1 Molecule structures ............................... 109

4.2.2 Physical and chemical properties ..................... 111

4.2.3 Synthesis methods ............................... 113 
4.2.3.1 Electric arc method........................ 113

4.2.3.2 Laser ablation method ...................... 113

4.2.3.3 Solar energy method....................... 114

4.2.4 Functionalization................................ 114

4.2.5 Possible risks .................................... 115

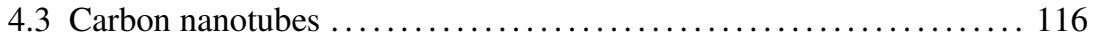

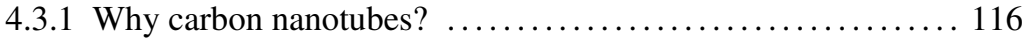

4.3.2 Structure of carbon nanotubes ...................... 117

4.3.3 Special properties of carbon nanotubes ................. 118

4.3.3.1 Chemical reactivity........................ 119

4.3.3.2 Electrical conductivity...................... 119

4.3.3.3 Optical activity.......................... 120

4.3.3.4 Vibrational properties ...................... 120

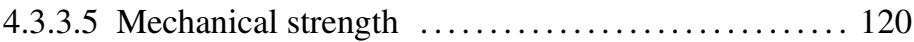

4.3.3.6 Specific heat and thermal conductivity ........... 121

4.3.4 Synthesis of carbon nanotubes....................... 121

4.3.4.1 Arc discharge method ..................... 122

4.3.4.2 Laser ablation method ...................... 124

4.3.4.3 Chemical vapor deposition method ............. 125

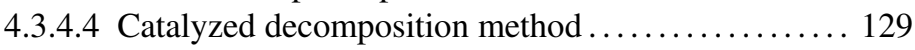

4.3.5 Purification of carbon nanotubes ....................... 133

4.3.5.1 Oxidation ................................ 133

4.3.5.2 Acid treatment ........................... 133

4.3.5.3 Annealing ................................. 134

4.3.5.4 Ultrasonication........................... 134

4.3.5.5 Magnetic purification....................... 134

4.3.5.6 Microfiltration ........................... 134

4.3.5.7 Cutting ................................ 135

4.3.5.8 Functionalization........................... 135

4.3.5.9 Chromatography .......................... 135

4.3.6 Defects of carbon nanotubes....................... 136

4.4 Carbon nanofoam ......................................... 136

4.4.1 Synthesis ........................................ 137

4.4.2 Properties...................................... 137

4.5 Applications....................................... 138

4.5.1 Fullerenes........................................ 139

4.5.2 Carbon nanotubes ................................. 139

4.5.2.1 Energy storage ............................ 139

4.5.2.2 Hydrogen storage.......................... 139

4.5.2.3 Lithium intercalation ....................... 140

4.5.2.4 Electrochemical supercapacitors ............... 141

4.5.2.5 Molecular devices with CNTs .................. 141 
4.5.2.6 Nanoelectromechanical systems ............... 142

4.5.2.7 Composite materials....................... 145

4.5.2.8 Templates ............................. 146

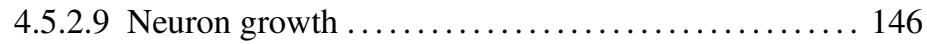

4.5.3 Carbon nanofoam ............................. 147

5. Nanostructured Materials $\quad 153$

5.1 Introduction ....................................... 153

5.1.1 Classifications of nanostructured materials .............. 153

5.1.2 Top-down and bottom-up synthesis approaches........... 154

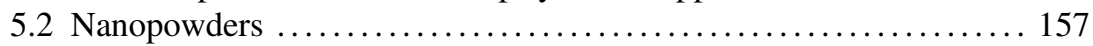

5.2.1 Properties of nanopowders ........................ 157

5.2 .2 Synthesis of nanopowders $\ldots \ldots \ldots \ldots \ldots \ldots \ldots \ldots \ldots \ldots \ldots \ldots \ldots$

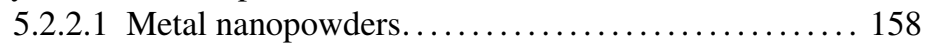

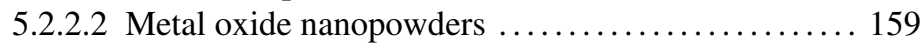

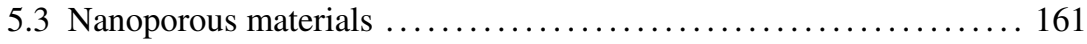

5.3.1 Properties of nanoporous materials . ................... 161

5.3.2 Synthesis of nanoporous materials ................... 162

5.3 .2 .1 Silica.................................. 163

5.3.2.2 Transition metal oxides...................... 164

5.3.2.3 Metal sulfides ............................ 164

5.3.2.4 Aluminum phosphates....................... 165

5.2.3.5 Silicon nitrides ........................... 165

5.3.2.6 Anodic aluminum oxides .................... 165

5.3.2.7 Metals ................................. 166

5.4 Nanodusts .......................................... 166

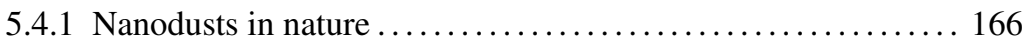

5.4 .2 Synthesis of nanodusts ........................... 167

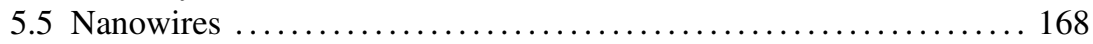

5.5.1 Classifications of nanowires....................... 168

5.5.2 Synthesis of nanowires........................... 169

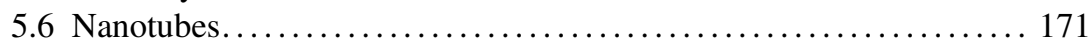

5.6.1 Classification of nanotubes...................... 172

5.6.2 Synthesis of inorganic nanotubes ................... 172

5.7 Zinc oxide nanostructures ............................. 174

5.8 Applications....................................... 176

5.8 .1 Nanopowders ................................. 176

5.8.2 Nanoporous materials ........................... 178

5.8 .3 Nanodusts ....................................... 179

5.8.3.1 Energy ................................. 179

5.8.3.2 Pollution control ......................... 180 
5.8.3.3 Nuclear protection....................... 180

5.8.3.4 Composite reinforcement .................. 180

5.8 .4 Nanowires .................................... 181

5.8 .5 Inorganic nanotubes............................. 181

5.8.5.1 Control of bio-interactions .................. 183

5.8.5.2 Growth of neuron cells ...................... 184

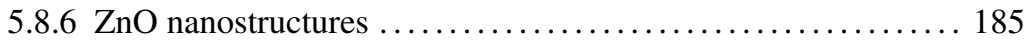

6. Polymer Nanotechnology 191

6.1 Electroactive polymers ................................ 191

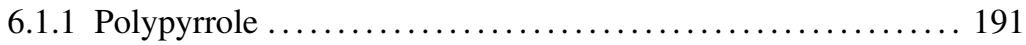

6.1 .2 Nafion ..................................... 192

6.2 Fabrication of polymer nanowires ....................... 192

6.2.1 Electrochemical polymerization ..................... 193

6.2 .2 Critical point drying............................. 193

6.3 Fabrication of polymer nanotubes........................ 197

6.3.1 Blank polymer nanotubes ....................... 198

6.3.2 Metal nanowires encapsulated in polymer nanotubes........ 203

6.4 Fabrication of 3D polymer microstructures................... 205

6.4 .1 Microstereolithography .......................... 205

6.4.2 Two-photon microstereolithography................. 207

7. Nanocomposites $\quad 215$

7.1 Nanoscale reinforcements ............................. 216

7.1.1 Nanoscale carbons ............................... 216

7.1 .2 Nano clays .................................... 217

7.1.3 Equi-axed nanoparticles........................... 218

7.2 Ceramic matrix nanocomposites ......................... 219

7.2.1 Synthesis methods .............................. 220

7.2.1.1 Sol-gel processing ........................ 221

7.2.1.2 Chemical vapor deposition .................. 221

7.2.1.3 Mechanical alloying....................... 221

7.2.1.4 Thermal spraying.......................... 222

7.2.2 CNT reinforced CNCs ........................... 223

7.2.3 Thin film nanocomposites......................... 224

7.2.3.1 Granular films........................... 224

7.2.3.2 Multi-layer films ......................... 225

7.3 Metal matrix nanocomposites........................... 225

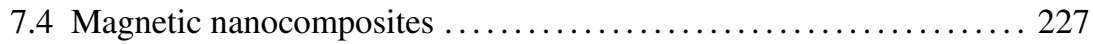

7.4.1 Particle-dispersed magnetic nanocomposites............. 227

7.4.2 Magnetic multi-layer films ....................... 227 
7.5 Polymeric nanocomposites ............................ 228

7.5.1 Synthesis of polymeric nanocomposites .............. 230

7.5.1.1 Melt mixing method ...................... 230

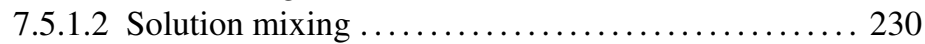

7.5.1.3 In-situ polymerization ...................... 231

7.5.1.4 In-situ particle processing ................... 231

7.5.1.5 Thermal spray method ..................... 231

7.5.1.6 Template method......................... 231

7.5.2 Typical properties of polymeric nanocomposites........... 232

7.5.2.1 Mechanical properties ..................... 232

7.5.2.2 Glass transition and relaxation behavior.......... 232

7.5.2.3 Abrasion and wear resistance ................ 233

7.5.2.4 Permeability............................. 233

7.5.2.5 Dimensional stability ...................... 234

7.5.2.6 Thermal stability and flammability............. 234

7.5.2.7 Resistivity, permittivity and breakdown strength .... 235

7.5.2.8 Optical clarity .......................... 235

7.5.3 Clay reinforced PNCs ............................ 236

7.5.4 CNT reinforced PNCs.............................. 237

7.5.5 Rubber matrix nanocomposites..................... 237

7.5.6 Stealth PNCs..................................... 238

7.6 Nano-bio-composites................................. 239

7.6.1 Botanically synthesized nanoparticles ................ 240

7.6.2 Biologically synthesized nanostructures ............... 240

7.7 Smart and intelligent nanocomposites..................... 241

8. Organic Electronics $\quad \mathbf{2 4 5}$

8.1 Introduction ........................................ 245

8.2 Morphology of pentacene thin film ...................... 248

8.3 OTFT fabrication.................................... 250

8.4 Typical organic sensors................................ 255

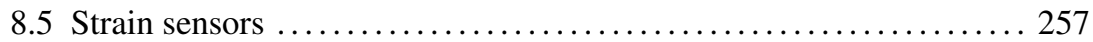

8.5.1 Carbon nanotube synthesis ........................ 257

8.5.1.1 Apparatus .............................. 257

8.5.1.2 Catalyst preparation ....................... 258

8.5.1.3 Microwave CVD synthesis and purification........ 259

8.5.1.4 Electron microscope observation............... 259

8.5.2 Organic strain sensor fabrication .................... 260

8.5.3 Sensor measurement ............................ 262

8.6 Poly-3-hexylthiophene based ISFET sensors .................. 264

8.6.1 Biomedical applications .......................... 265 
8.6.2 Poly-3-hexylthiophene as a semiconducting polymer ....... 265

8.6.3 Tantalum oxide as gate dielectric ..................... 266

8.6.4 Enzyme immobilization ........................... 267

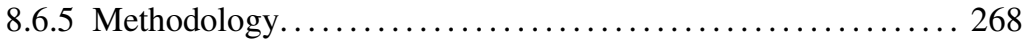

8.6 .6 Results...................................... 269

$\begin{array}{ll}\text { Glossary } & 275\end{array}$

$\begin{array}{ll}\text { Index } & 293\end{array}$ 